\title{
Correction to: Fluorescence anisotropy study of radiation-induced DNA damage clustering based on FRET
}

\author{
Ken Akamatsu $^{1}$ - Naoya Shikazono ${ }^{1}$ - Takeshi Saito ${ }^{2}$ \\ Received: 9 March 2021 / Accepted: 9 March 2021 / Published online: 13 March 2021
}

(C) Springer-Verlag GmbH Germany, part of Springer Nature 2021

\section{Correction to: Analytical and Bioanalytical Chemistry https://doi.org/10.1007/s00216-020-03082-w}

The authors would like to call the reader's attention to the fact that, unfortunately, there was an error regarding figure 3 in this manuscript; please find the correct figure below. The apparent base separation in a cluster produced by $2.0 \mathrm{MeV} / \mathrm{u}$ ${ }^{4} \mathrm{He}^{2+}, 0.52 \mathrm{MeV} / \mathrm{u}^{4} \mathrm{He}^{2+}$, and $0.37 \mathrm{MeV} / \mathrm{u}^{12} \mathrm{C}^{5+}$ beams demonstrated in the "Abstract" and the "Results and Discussion" sections are changed to be ca. 21,19 , and $18 \mathrm{bp}$, respectively.

Publisher's note Springer Nature remains neutral with regard to jurisdictional claims in published maps and institutional affiliations.

The online version of the original article can be found at https://doi.org/ 10.1007/s00216-020-03082-w

Ken Akamatsu

akamatsu.ken@qst.go.jp

1 DNA Damage Chemistry Research Group, Institute for Quantum Life Science, National Institutes for Quantum and Radiological Science and Technology (QST), 8-1-7 Umemidai, Kizugawa, Kyoto 619-0215, Japan

2 Division of Radiation Life Science, Institute for Integrated Radiation and Nuclear Science, Kyoto University, 2 Asashiro-Nishi, Kumatori, Sennan, Osaka 590-0494, Japan 

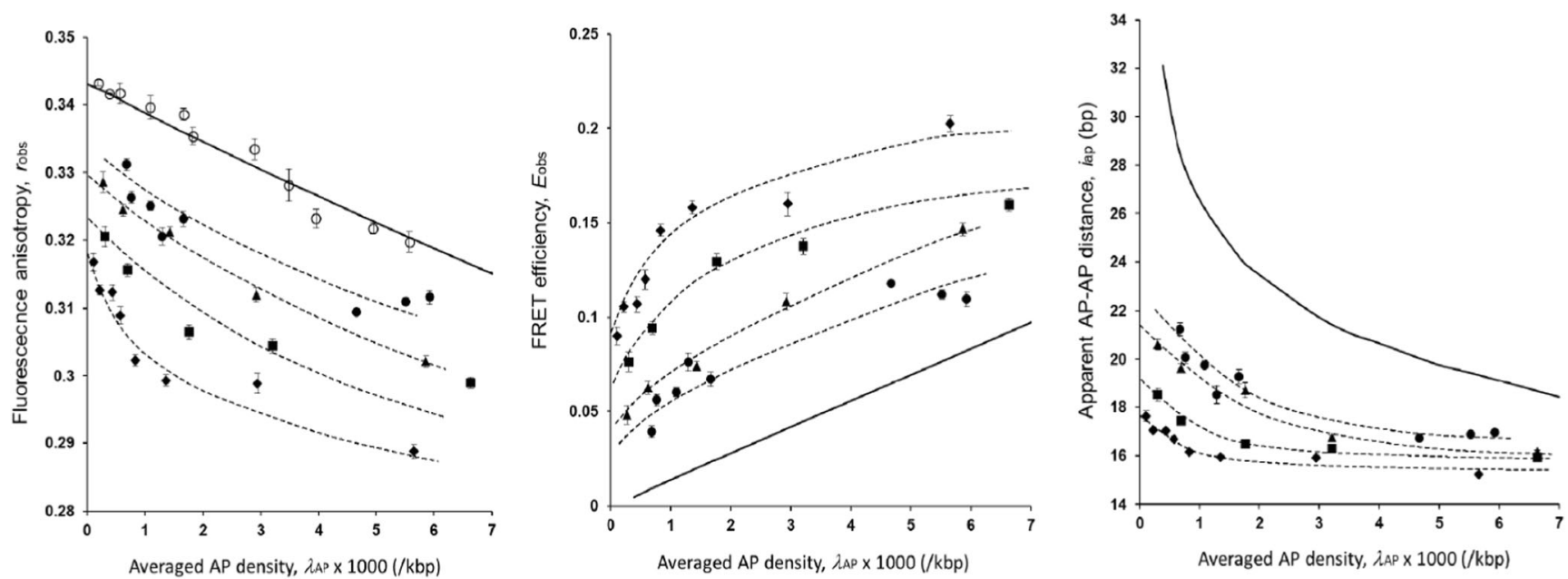